\title{
The effect of thermal dose on hyperthermia-mediated inhibition of DNA repair through homologous recombination
}

\author{
Nathalie van den Tempel $^{1}$, Charlie Laffeber $^{1}$, Hanny Odijk ${ }^{1}$, Wiggert A. van \\ Cappellen ${ }^{2}$, Gerard C. van Rhoon ${ }^{3}$, Martine Franckena ${ }^{3}$ and Roland Kanaar ${ }^{1}$ \\ ${ }^{1}$ Department of Molecular Genetics, Cancer Genomics Center Netherlands, Erasmus University Medical Center, 3000 CA, \\ Rotterdam, The Netherlands \\ ${ }^{2}$ Optical Imaging Center, Department of Pathology, Erasmus University Medical Center, 3000 CA, Rotterdam, The Netherlands \\ ${ }^{3}$ Department of Radiation Oncology, Erasmus MC Cancer Institute, 3008 AE, Rotterdam, The Netherlands \\ Correspondence to: Roland Kanaar, email: r.kanaar@erasmusmc.nl
}

Keywords: hyperthermia, thermal dose, homologous recombination, BRCA2, RAD51

Abbreviations: HR: homologous recombination; ROI: region of Interest

Received: March 08, $2017 \quad$ Accepted: April 26, $2017 \quad$ Published: May 15, 2017

Copyright: van den Tempel et al. This is an open-access article distributed under the terms of the Creative Commons Attribution License 3.0 (CC BY 3.0), which permits unrestricted use, distribution, and reproduction in any medium, provided the original author and source are credited.

\section{ABSTRACT}

Hyperthermia has a number of biological effects that sensitize tumors to radiotherapy in the range between $40-44{ }^{\circ} \mathrm{C}$. One of these effects is heat-induced degradation of BRCA2 that in turn causes reduced RAD51 focus formation, which results in an attenuation of DNA repair through homologous recombination. Prompted by this molecular insight into how hyperthermia attenuates homologous recombination, we now quantitatively explore time and temperature dynamics of hyperthermia on BRCA2 levels and RAD51 focus formation in cell culture models, and link this to their clonogenic survival capacity after irradiation (0-6 Gy). For treatment temperatures above $41{ }^{\circ} \mathrm{C}$, we found a decrease in cell survival, an increase in sensitization towards irradiation, a decrease of BRCA2 protein levels, and altered RAD51 focus formation. When the temperatures exceeded $43{ }^{\circ} \mathrm{C}$, we found that hyperthermia alone killed more cells directly, and that processes other than homologous recombination were affected by the heat. This study demonstrates that optimal inhibition of HR is achieved by subjecting cells to hyperthermia at $41-43{ }^{\circ} \mathrm{C}$ for $\mathbf{3 0}$ to $\mathbf{6 0}$ minutes. Our data provides a guideline for the clinical application of novel combination treatments that could exploit hyperthermia's attenuation of homologous recombination, such as the combination of hyperthermia with PARP-inhibitors for non-BRCA mutations carriers.

\section{INTRODUCTION}

Hyperthermia is an anti-cancer treatment during which external heat sources are employed to treat tumors. During the treatment, specialized equipment is used to regionally heat the tumor to a final temperature in the range of $40-44^{\circ} \mathrm{C}$ [1], which is a safe and effective way to enhance the effectiveness of radiotherapy and some types of chemotherapy, such as cisplatin, carboplatin, cyclophosphamide, ifosfamide, melphalan and mitomycin C $[2,3]$. Hyperthermia's sensitization effects towards radiotherapy and chemotherapy can be attributed to a plethora of biological effects in the tumor, both on a macroscopic and microscopic scale. Research that aims to elucidate the biological effects of heat has the potential to revolutionize the way in which hyperthermia will be employed in a clinical setting [4-8].

One of the effects of hyperthermia described more recently is the induction of degradation of the BRCA2protein [9]. BRCA2 is essential for repair of DNA double strand breaks via homologous recombination (HR) [10]. HR faithfully restores these breaks by copying the 
information from an intact copy of the damaged DNA, a process catalyzed by the protein RAD51 [11]. BRCA2 is necessary for the loading of RAD51 onto DNA breaks and by degrading BRCA2, hyperthermia causes aberrant localization of RAD51 [9]. This, in turn, causes the attenuation of DNA repair via $H R$, which at least partly explains hyperthermia's sensitizing effects towards radiotherapy, the latter being based on the creation of an overload of cytotoxic DNA breaks in tumor cells. DNA repair pathways can counteract the cytotoxicity, and thus, by degrading BRCA2, hyperthermia provides a window of opportunity to leave DNA damage unrepaired. Moreover, hyperthermia-mediated BRCA2 degradation creates specific opportunities to increase treatment efficacy, because it induces a localized environment of HR-deficiency. This could potentially be exploited by new treatment regimens that reduce cancer treatment sideeffects, such as combination of hyperthermia with new classes of indirect double-strand break inducing agents, like PARP-inhibitors [12, 13].

Before exploiting hyperthermia-mediated attenuation of $\mathrm{HR}$ in a clinical setting, it is important to understand the dynamics of BRCA2 degradation and HR-efficiency upon exposures to different temperatures and treatment lengths, or, thermal doses. By using a set of in vitro experiments, we systematically investigated the effects of various thermal doses (ranging from $40-44{ }^{\circ} \mathrm{C}$ for up to four hours) on HR-parameters such as BRCA2 degradation and RAD51 focus formation, and we examined the extent of cellular sensitization towards radiation. Our findings provide insight into threshold and saturation levels of BRCA2 degradation upon heat treatment and thereby give insight into the relation between thermal dose and HR-efficiency.

\section{RESULTS}

\section{Thermal dose is a determinant for radiosensitisation}

To investigate the influence of thermal dose on HR, we first established the thermal doses to be used in this study (Table 1). Because we are interested in the influence of thermal doses currently achieved and aimed for in a clinical setting, we selected them based on temperatures in the range of $40-44{ }^{\circ} \mathrm{C}$, and on the current duration of 60 minutes. Additional lengths of treatment were chosen to determine an optimum dose for HR-inhibition.

To provide a framework for the assays in which we will determine inhibition of HR by hyperthermia, we established the ability of these selected thermal doses to kill cells directly, and determined their capability to sensitize cells to irradiation. To get a general overview of the biological principles that guide inhibition of HR by hyperthermia, we combined the results of four different cell lines. We started by establishing colony survival curves of three different cell lines that represent various cancer types that are treated with hyperthermia: BLM (melanoma), HeLa (cervix) and FaDu (head and neck), and a cell line that represents a p53-negative tumor: simian virus 40-immortalized fibroblasts (VH10-SV40). We treated the cells with the selected thermal doses and with doses of radiation ranging from $0-6 \mathrm{~Gy}$. Consistent with previous studies [14-16], the colony plating efficiency for each cell line was reduced after treatment with temperatures higher than $40{ }^{\circ} \mathrm{C}$ (Figure 1A), demonstrating hyperthermia's ability to kill cells directly.

To closely examine radiosensitisation by hyperthermia, we normalized each colony survival curve belonging to a certain thermal dose for plating efficiency at 0 Gy to $100 \%$ (Supplementary Figure 1). We then combined the data points from all four cell lines, and fitted a linear-quadratic curve to the pooled data (Figure 1B) [17]. This analysis resulted in an overview of the response to heat and irradiation in the employed cell lines: hyperthermia at $40{ }^{\circ} \mathrm{C}$ failed to increase sensitivity to irradiation, indicated by the prediction of one curve to explain the data variation [17]. For all thermal doses employing temperatures higher than $41^{\circ} \mathrm{C}$ multiple curves were obtained, indicating these thermal doses sensitized the tumor cells to irradiation. The maximum extent of radiosensitisation at $41{ }^{\circ} \mathrm{C}$ was reached after two hours of treatment, while the same effect was already reached after one hour at $42{ }^{\circ} \mathrm{C}$. Doubling the treatment times did not increase radiosensitisation any further, indicating a saturation of the effects of heat over time. The timedependent saturation was not observed when cells were treated with $43{ }^{\circ} \mathrm{C}, 43.5^{\circ} \mathrm{C}$ or $44{ }^{\circ} \mathrm{C}$ (Figure 1B).

\section{Temperatures higher than $40^{\circ} \mathrm{C}$ cause significant degradation of functional BRCA2 proteins}

Hyperthermia at $42.5^{\circ} \mathrm{C}$ inhibits HR by inducing proteasomal degradation of the BRCA2 protein [9]. To study the effects of thermal dose on HR, we started by examining the ability of the selected thermal doses to induce degradation of the BRCA2 protein, by measuring the BRCA2-protein levels in whole cell extracts from the four cell lines treated with the thermal doses by immunoblot (Figure 2A). We quantified the BRCA2signals on the immunoblot and normalized these to the signal at $37^{\circ} \mathrm{C}$ (Figure 2B). Although each thermal dose had an effect on BRCA2 protein level, the extent of the effect was quite different. For the four cell lines tested, the lowest mean BRCA2 protein level (22\%) was reached after 60 minutes treatment at $43{ }^{\circ} \mathrm{C}$, while as much as $64 \%$ of the BRCA2 signal remained after four hours of treatment at $40{ }^{\circ} \mathrm{C}$ (Figure 2B). This indicates that BRCA2 degradation is dependent on the applied thermal dose, and presumably, that treatment at $40{ }^{\circ} \mathrm{C}$ might be insufficient to achieve a significant reduction in BRCA2 protein levels and thereby in HR. Upon examination of 
Table 1: Contains an overview of the thermal doses employed in this study

\begin{tabular}{lcccc}
\hline Temperature & Time $\mathbf{0}\left(\mathbf{3 7}{ }^{\circ} \mathbf{C}\right)$ & Time $\mathbf{1}$ & Time $\mathbf{2}$ & Time 3 \\
\hline $\mathbf{4 0}^{\circ} \mathbf{C}$ & $0 \mathrm{~min}$ & $60 \mathrm{~min}$ & $120 \mathrm{~min}$ & $240 \mathrm{~min}$ \\
$\mathbf{4 1}{ }^{\circ} \mathbf{C}$ & $0 \mathrm{~min}$ & $60 \mathrm{~min}$ & $120 \mathrm{~min}$ & $240 \mathrm{~min}$ \\
$\mathbf{4 2}^{\circ} \mathbf{C}$ & $0 \mathrm{~min}$ & $30 \mathrm{~min}$ & $60 \mathrm{~min}$ & $120 \mathrm{~min}$ \\
$\mathbf{4 3}^{\circ} \mathbf{C}$ & $0 \mathrm{~min}$ & $15 \mathrm{~min}$ & $30 \mathrm{~min}$ & $60 \mathrm{~min}$ \\
$\mathbf{4 3 . 5}^{\circ} \mathbf{C}$ & $0 \mathrm{~min}$ & $15 \mathrm{~min}$ & $30 \mathrm{~min}$ & $60 \mathrm{~min}$ \\
$\mathbf{4 4}^{\circ} \mathbf{C}$ & $0 \mathrm{~min}$ & $15 \mathrm{~min}$ & $30 \mathrm{~min}$ & $60 \mathrm{~min}$ \\
\hline
\end{tabular}

A

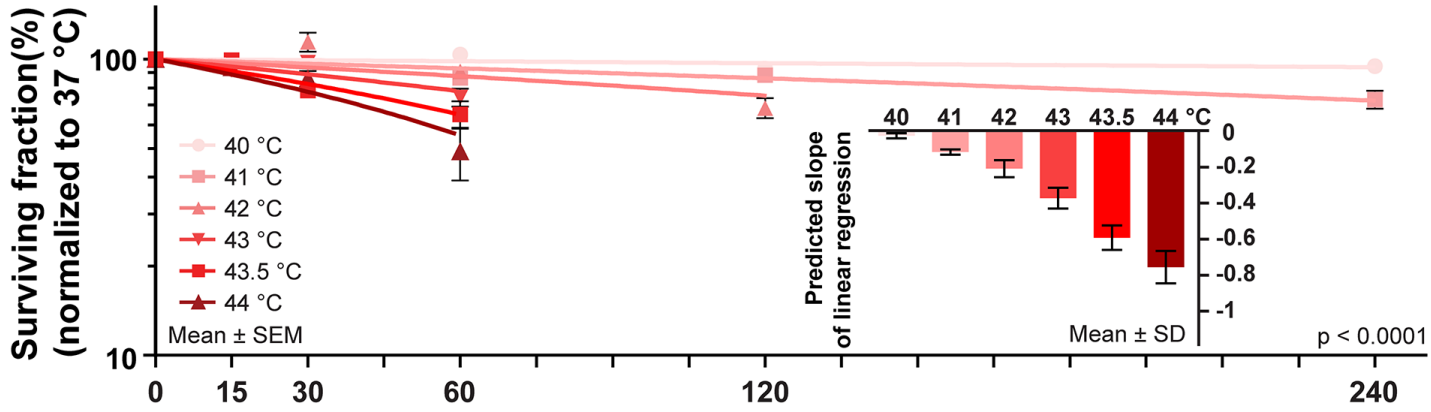

B

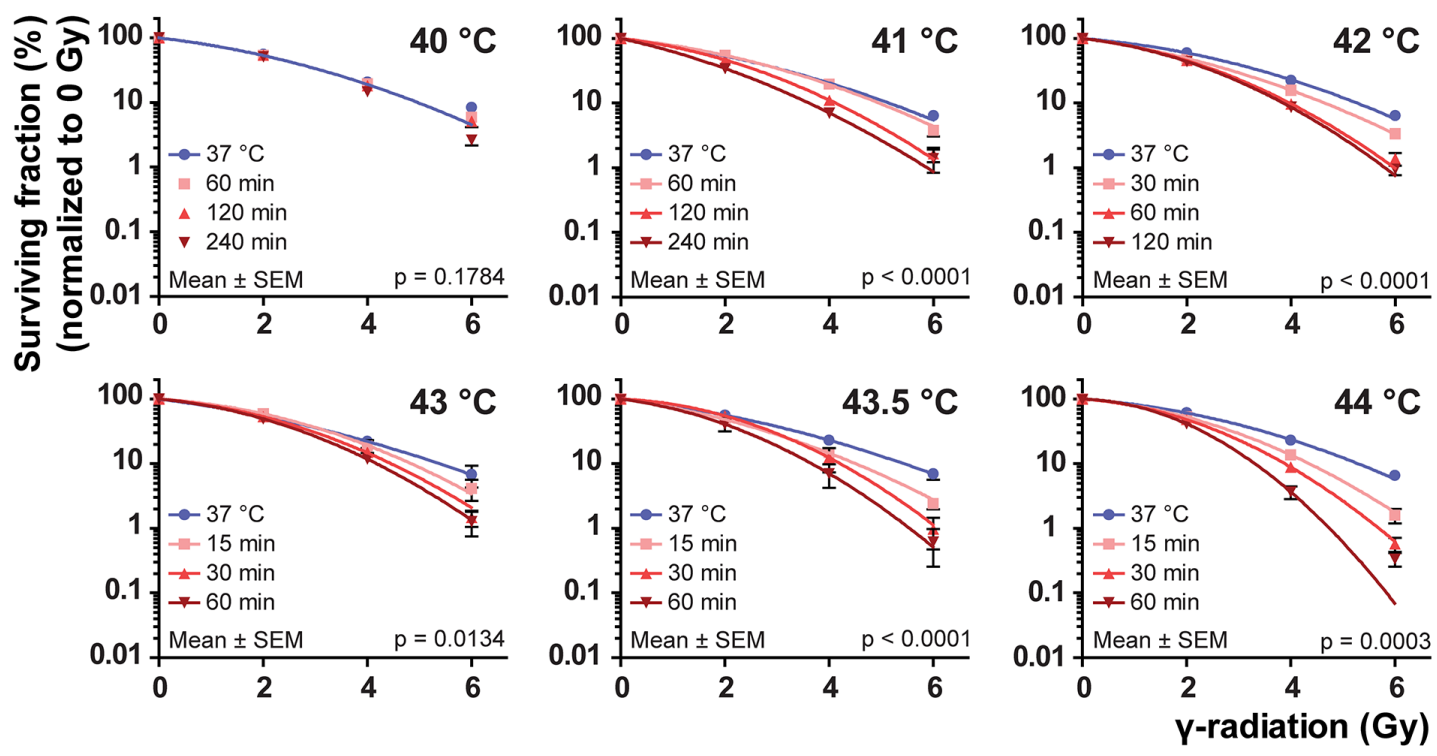

Figure 1: Plating efficiency and colony cell survival at different thermal doses. Four different cell lines (BLM, HeLa, FaDu and VH10-SV40) were submitted to hyperthermia and irradiated afterwards in six independent experiments; one for each temperature. The data points and error bars represent mean $\pm \mathrm{SEM}$ of all pooled cell lines and the connecting curve is the result of a fitted regression. Multiple curves were predicted if the regression parameters differed significantly from each other $(\mathrm{p}<0.05)$. Exact $\mathrm{p}$-value is embedded in the graphs. (A) Plating efficiencies at $0 \mathrm{~Gy}$ for all temperatures, normalized to $37{ }^{\circ} \mathrm{C}$. Curves were predicted by linear regression and the inset graph shows the predicted slope of the regression analysis (Mean \pm SD). (B) Surviving fractions upon irradiation, normalized to 0 Gy for each thermal dose. The curves are predictions made by linear-quadratic regression. At $40{ }^{\circ} \mathrm{C}$, the single curve explains the variation in the data. Between the experiments, one regression line was predicted to explain survival towards irradiation at $37^{\circ} \mathrm{C}$. Clonogenic survival curves for the individual cell lines can be found in Supplementary Figure 1. 
the BRCA2 protein levels after treatment for 60 minutes at the different temperatures, we noticed the most significant decrease in the level between $41^{\circ} \mathrm{C}$ and $42{ }^{\circ} \mathrm{C}$ (Figure 2C). Interestingly, when temperatures surpassed $42{ }^{\circ} \mathrm{C}$, the degradation of BRCA2 observed in the whole cell lysates seemed similar or even less efficient than at $42{ }^{\circ} \mathrm{C}$ itself, which is especially pronounced in $\mathrm{FaDu}$ cells (Figure 2C).
We therefore investigated whether the BRCA2signal in the whole cell extract at temperatures exceeding $43{ }^{\circ} \mathrm{C}$ represents a functional pool of the BRCA2 protein. Since degradation of BRCA2 is mediated by the proteasome, a heat-mediated malfunction of proteasomes could lead to a failure to detect declining BRCA2-signals in a whole cell extract. When the proteasome inhibitor

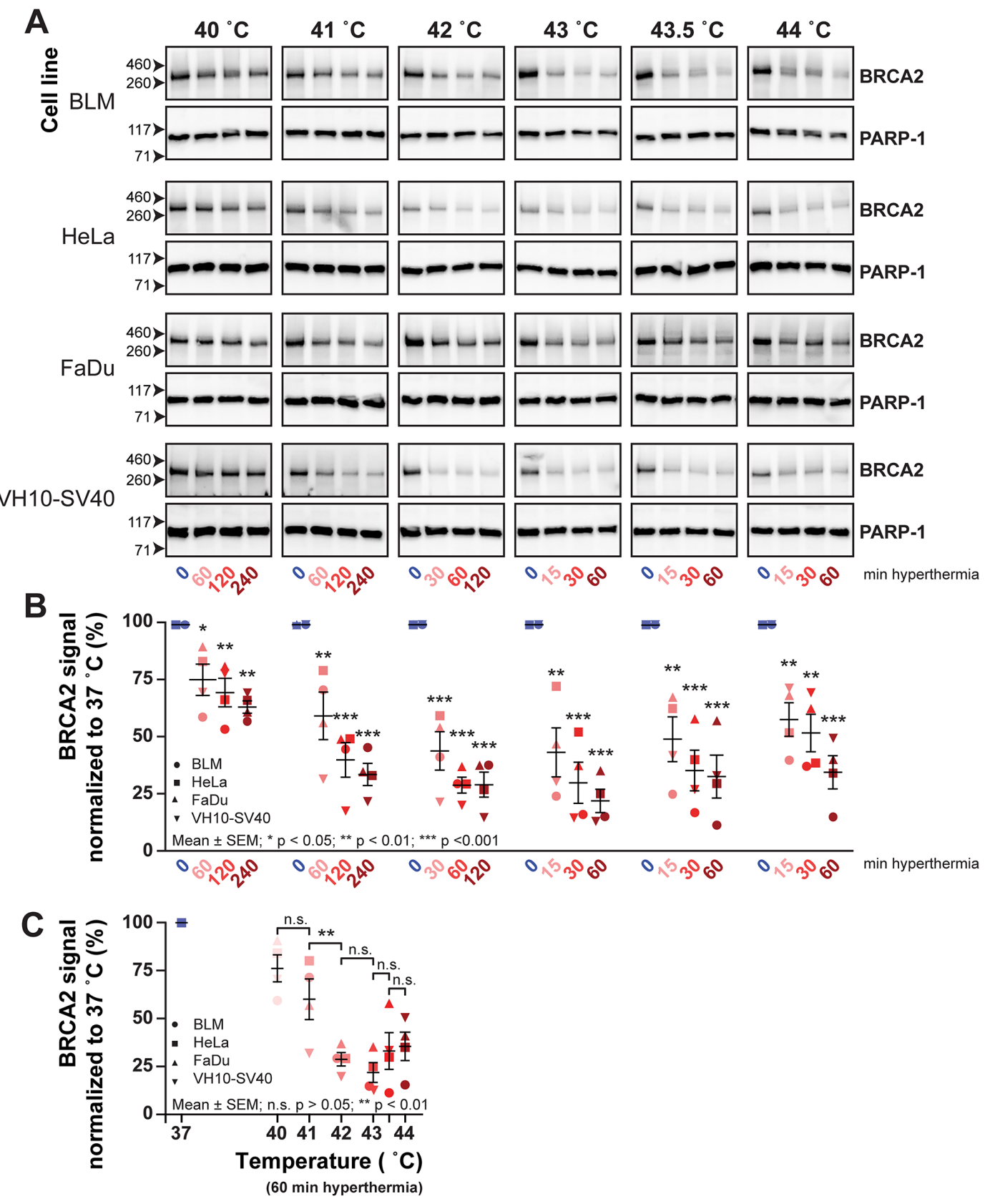

Figure 2: The BRCA2 protein is degraded at temperatures higher than $40{ }^{\circ} \mathrm{C}$. Cells from four different lines BLM (circle), HeLa (square), FaDu (triangle), VH10-SV40 (inverted triangle) were submitted to hyperthermia and subsequently lysed in six separate experiments; one for each temperature. (A) BRCA2-signals of all separate samples on cropped immunoblots. PARP-1 is used as a loading control. (B) Quantification of BRCA2-protein signals from A Each hyperthermia-treated sample is represented as a percentage of the BRCA2 signal at $37{ }^{\circ} \mathrm{C}$. The error bars denote mean \pm SEM. The statistical differences relative to $37{ }^{\circ} \mathrm{C}$ were determined by ANOVA and followed by Tukey's Multiple Comparison Test. (C) Quantification of BRCA2 after 60 minutes of a given temperature. Statistical differences were determined by ANOVA and followed by Tukey's Multiple Comparison test. 
MG132 is added to cells previous to hyperthermia treatment, the BRCA2-protein levels are rescued in a whole cell extract [9]. However, when the cell lysates from cells treated with MG132 and hyperthermia are fractionated, the entire fraction of protected BRCA2 is found in the pellet instead of in the supernatant, indicating that the heat caused the protein to become insoluble (Figure 3A). To investigate what happens with the BRCA2-proteins found at $44{ }^{\circ} \mathrm{C}$, we performed the same simple fractionation of HeLa cells treated with the thermal doses employing temperatures of $42^{\circ} \mathrm{C}$ and $44^{\circ} \mathrm{C}$ (Figure 3B and 3C).
The reduction of the $\mathrm{BRCA} 2$ signal in the whole cell extract in this experiment was clearly visible when the cells were treated with $42^{\circ} \mathrm{C}$ and $44{ }^{\circ} \mathrm{C}$ (Figure 3B). However, cells treated for 60 minutes at $42{ }^{\circ} \mathrm{C}$ seemed to have lower BRCA2-levels than cells treated for 60 minutes at $44{ }^{\circ} \mathrm{C}$, confirming our results from Figure 2C. Strikingly, the localization of BRCA2 in the extracts was very different: we found that the BRCA2 levels in the supernatant were lower at $44{ }^{\circ} \mathrm{C}$ than at $42{ }^{\circ} \mathrm{C}$, indicating that the higher temperature is a stronger inducer of BRCA2-degradation (Figure 3C and 3D). In contrast to the supernatant, the BRCA2 protein detected in the pellet
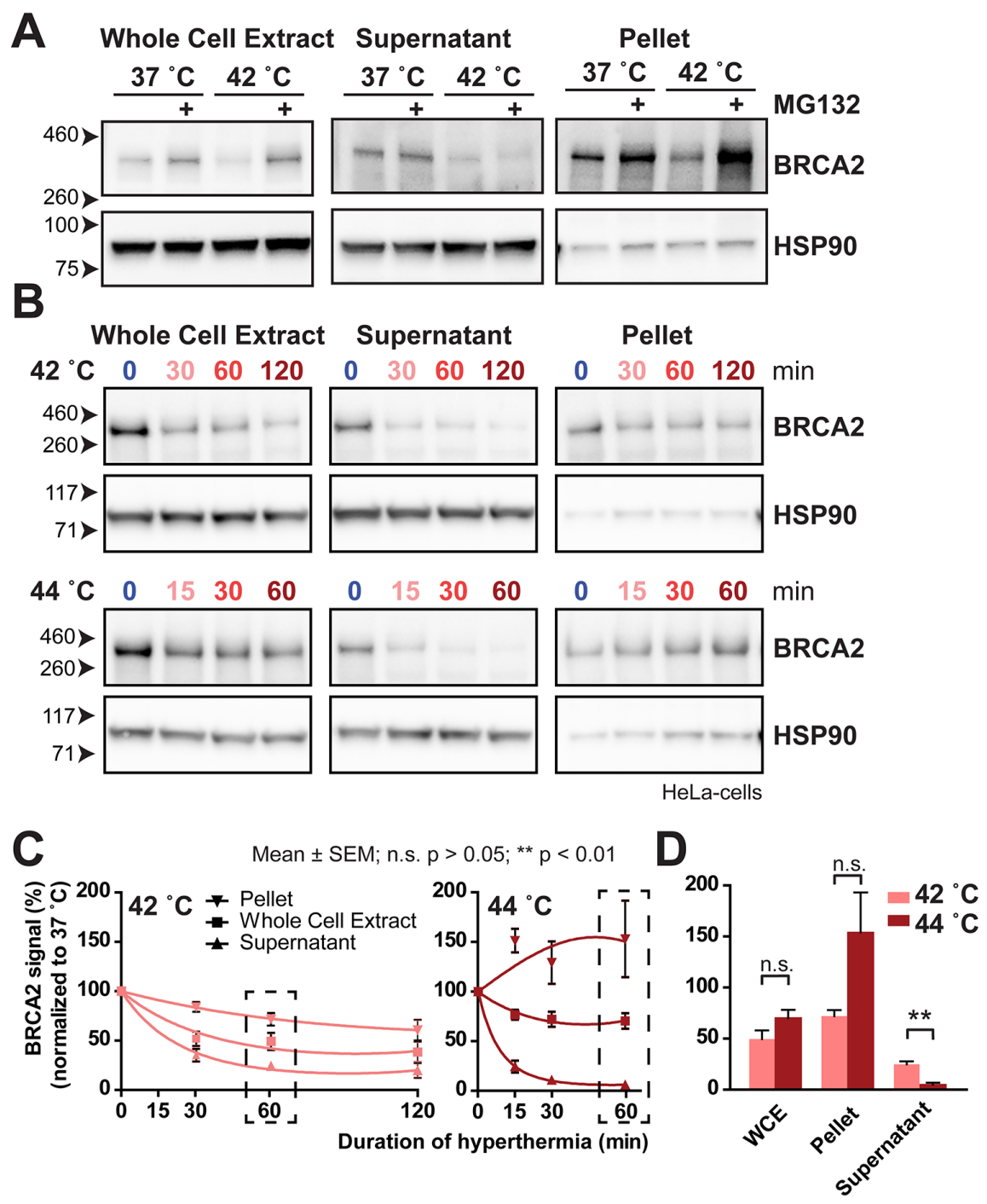

Figure 3: BRCA2 moves to an insoluble fraction after treatment with $\mathrm{MG} 132$ or $44{ }^{\circ} \mathrm{C}$. (A) $\mathrm{BRCA} 2$ protein levels at $37{ }^{\circ} \mathrm{C}$ and $42{ }^{\circ} \mathrm{C}$ in HeLa cells treated with or without $50 \mu \mathrm{M}$ MG132 on cropped immunoblots. Signals shown are from the whole cell extract (left), and from two fractions after centrifugation: the supernatant (middle) and in the pellet fraction (right). HSP90 is used as a loading control. (B) BRCA2 protein levels on cropped immunoblots at $42{ }^{\circ} \mathrm{C}$ (upper panel) and $44{ }^{\circ} \mathrm{C}$ (lower panel) in HeLa cells in the whole cell extract (left), and from the two fractions after centrifugation: the supernatant (middle) and in the pellet fraction (right). HSP90 is shown as a loading control. (C) Quantification of BRCA2 signals in B, corrected for the $37{ }^{\circ} \mathrm{C}$ control. A linear-quadratic regression indicates three separate curves for each series of measurements, indicating a significant difference in BRCA2-protein levels in the whole cell extract, supernatant and pellet. The error bars denote mean \pm SEM obtained in three experiments. (D) Bars zoom in on the 60-minute treatment point in C. Statistical differences of column pairs were determined using a student's $t$-test. 
increased over time when temperature was set from 37 to $44{ }^{\circ} \mathrm{C}$, while it decreased over time when cells were treated with $42{ }^{\circ} \mathrm{C}$ (Figure 3C). This finding indicates that although the BRCA2 protein is still present in the whole cell extract at the higher temperatures, it represents a pool of protein that has aggregated in a fraction that ends up in the pellet, and is therefore unlikely to be functional.

\section{Localization of RAD51 in cells is differentially affected by thermal dose}

Because we found different levels of BRCA2 protein in response to different thermal doses, and found that temperatures exceeding $43{ }^{\circ} \mathrm{C}$ did not completely eradicate BRCA2 protein levels in the whole cell extract (Figure 3), we investigated the presence of RAD51 foci upon treatment with the different thermal doses. These foci represent the localization of the RAD51-protein onto DNA double strand breaks and are a read-out for effectivity of HR, in particular for the functionality of the BRCA2-protein [18]. Correlating to BRCA2-degradation upon hyperthermia treatment $\left(41-42{ }^{\circ} \mathrm{C}\right)$, RAD51 fails to localize onto double strand breaks in cells treated at these temperatures [9]. To investigate the appearance and behavior of RAD51 foci upon treatment with the various thermal doses, we treated HeLa cells with these doses, irradiated them with 4 Gy, and fixed them either 30, 60 or 120 minutes after the irradiation. HR requires a copy of the damaged DNA, usually the sister chromatid, and is therefore limited to the S- and G2-phase of the cell cycle [11]. Therefore, to confirm the cells' ability to form RAD51 foci, we used a positive signal for incorporated EdU as a prerequisite for cells to be analyzed.

Upon examining the RAD51 signal in the EdUpositive cells, we found three very distinguished focipatterns, which we refer to as Category 1-3 foci. Cells in Category 1 presented with many large foci, or "normal", based on our extensive experience [19-21]. Cells with the Category 2 focus pattern displayed fewer, but quite large foci. The Category 3 focus pattern was represented by cells with many, but mostly very small foci (Figure 4A). To objectively describe these focus structures, we designed an image analysis tool that measures several aspects of RAD51 foci in a cell nucleus: the number of foci, their average area and their average intensity (Supplementary Figure 2). Since both area and intensity can be used to classify the response of the foci to temperature, we combined them by multiplication, resulting in the mean integrated density per focus per nucleus. We plotted the integrated density and the number of RAD51 foci per cell in a 2D histogram (Figure 4B). While there is little to no difference between cells that received heat treatment at $40{ }^{\circ} \mathrm{C}$ or treatment at $37^{\circ} \mathrm{C}$, cells treated with hyperthermia at the higher temperatures (indicated by the cloud of red points), shifted away from the cells treated at $37{ }^{\circ} \mathrm{C}$ (cloud of blue points) (Figure 4B). Compared to cells that were treated at $37^{\circ} \mathrm{C}$, cells that were treated with $41{ }^{\circ} \mathrm{C}, 42{ }^{\circ} \mathrm{C}$, or, up to 15 minutes with $43{ }^{\circ} \mathrm{C}$ or $43.5^{\circ} \mathrm{C}$ had mostly fewer foci (Category 2) (Figure 4B). However, cells treated with $44{ }^{\circ} \mathrm{C}$ or with more than 15 minutes at 43 or $43.5^{\circ} \mathrm{C}$ had foci that were smaller in size and intensity (Category 3) (Figure 4B).

Upon examination of the Category 3-type foci, we noticed that they also were present in cells that had not been irradiated (Figure 4C), indicating that they form spontaneously upon heat treatment. The Category 3 RAD51 foci have been described earlier as a representation of stalled replication forks, which are able to form independently of functional BRCA2 protein [22]. These structures might therefore be additional proof for the hypothesis that hyperthermia with temperatures exceeding $43{ }^{\circ} \mathrm{C}$ causes problems in the S-phase of the cells [16]. Concordantly, we found that cells with Category 3 foci had a less intense EdU-signal compared to cells that had normal foci (Category 1) or less foci (Category 2) (Supplementary Figure 2E). The EdU-signal did recover two hours after stopping hyperthermia treatment, hinting that the problems in S-phase could be reversible over time. This combined evidence suggests that the disappearance of the Category 1 RAD51 foci after treatment with temperatures higher than $40{ }^{\circ} \mathrm{C}$ indicates inhibited HR, and that the Category 3 foci represent another effect of hyperthermia.

\section{DISCUSSION}

The elucidation of the mechanisms of the biological processes responsible for the sensitizing effect of heat towards radiotherapy and various chemotherapies is an active field of research. Among these processes DNA repair pathways are attractive targets of hyperthermia because their activity modulates the cytotoxicity of DNA breaks in tumor cells, on which the efficacy of radiation and chemotherapy is based [23]. Although many DNA repair pathways are thought to be affected by heat, one pathway is of specific interest in this context: HR. This is because the discovery that hyperthermia can be used to locally and on demand inhibit the activity of the HR DNA repair pathway opens up avenues to novel combination therapies; specifically the combination of hyperthermia with PARP-inhibitors. PARP-inhibitors selective kill HR-deficient cells and are currently clinically applied for patient with HR-defective tumors due to genetic BRCA deficiency [24-26]. Inhibition of HR by hyperthermia carries the promise that PARP-inhibitors can be successfully used in much broader patient populations, as it will temporarily inactive HR, irrespective of the patient's genetic make-up $[9,12]$.

In this study, we systematically explored the influence of various thermal doses on HR by a set of in vitro experiments. We used two parameters of HR-effectivity: BRCA2 protein levels and RAD51 focus formation upon 
irradiation, and established survival curves at the same thermal doses to relate HR parameters to a functional outcome (Supplementary Table 1). Based on the obtained data employing the thermal doses, we can describe three distinct responses of HR towards hyperthermia.

The first response is a presumed failure to effectively attenuate HR. Cells heated at $40^{\circ} \mathrm{C}$ have more than $60 \%$ of the BRCA2 protein relative to the non-heated cells, and the formation of RAD51 foci is barely affected by this temperature. This correlates with the finding that hyperthermia at $40{ }^{\circ} \mathrm{C}$ does not significantly increase the sensitivity of the cells to irradiation. With respect to the survival results, it should be noted that the average treatment temperatures currently reached in the clinic, ranging between 40 and $41{ }^{\circ} \mathrm{C}$, does strongly enhance treatment outcome [27-32]. This could be explained by two reasons, the first being that the cells in culture are treated with hyperthermia and radiotherapy only once,
A
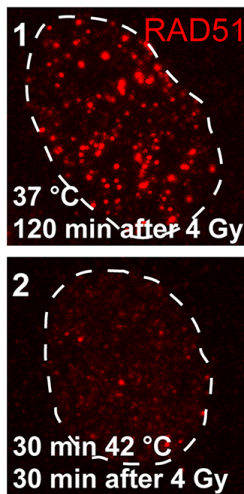

3

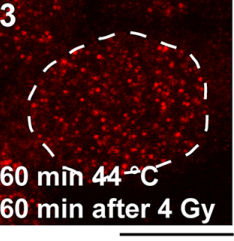

$10 \mu \mathrm{m}$

C
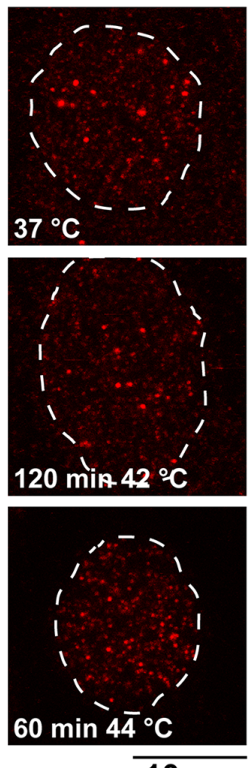

$10 \mu \mathrm{m}$

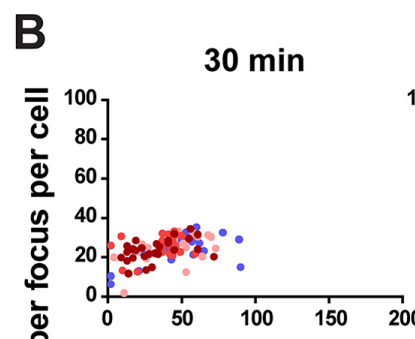

$60 \mathrm{~min}$
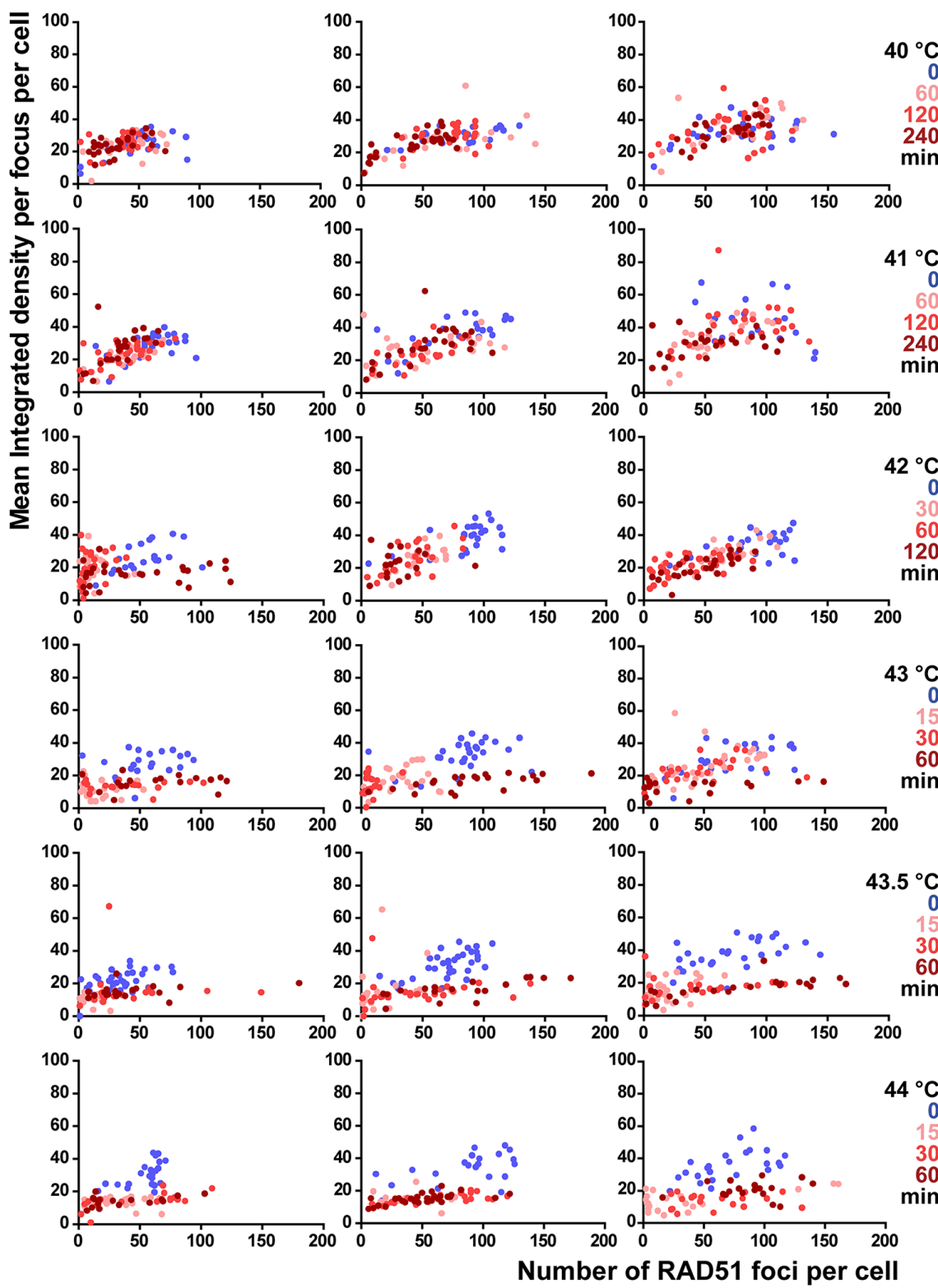

Figure 4: RAD51 foci behave differently depending on the thermal dose. (A) Representative pictures of RAD51-staining pattern upon 4 Gy irradiation in EdU-positive nuclei of HeLa cells. The RAD51 pattern shown in picture 1 is characterized as 'normal'. In picture 2 only few foci can be seen, and in picture 3, many, but mostly very small foci can be distinguished. (B) 2D-representation of measured focus-structures in EdU-positive cells. Each dot represents a cell, with on the X-axis the number of foci and on the Y-axis the mean integrated density per focus. Thermal doses are indicated with the different colors. A shift of the dot-cloud represents a different appearance or, qualification of the RAD51 focus. (C) Representative pictures of RAD51-staining pattern in EdU-positive nuclei in unirradiated cells. 
thus even small, non-significant differences in our colony survival assay could result in larger, significant effects when treatment is repeated multiple times, as is the case in the clinic. The second explanation is that hyperthermia has multiple biological effects, including increased blood flow [33], increased oxidation [34], and activation of the immune system [35], which are obviously not taken into account in our in vitro experimental set-up, but might very well mediate the treatment outcome in patients treated with hyperthermia at lower temperatures [5-8].

The second response group is characterized by an attenuation of $\mathrm{HR}$, and presents itself when cells are treated with $41{ }^{\circ} \mathrm{C}, 42{ }^{\circ} \mathrm{C}$ or with 15 or 30 minutes at 43 ${ }^{\circ} \mathrm{C}$. At $41{ }^{\circ} \mathrm{C}, 60 \%$ of the baseline BRCA2 levels remain after 60 minutes of treatment, and continue to drop with longer treatment times, as do the number and integrated density of RAD51 foci. Moreover, cells are sensitized to irradiation when they are treated for 60 minutes at $41{ }^{\circ} \mathrm{C}$, and this effect can be exaggerated when cells are treated for two hours. However, an additional two hours results only in a small decrease in survival, indicating a saturation of the hyperthermia-mediated effects on the cells. The effects of heat on cell survival and on HR in cells treated with hyperthermia at $42{ }^{\circ} \mathrm{C}$, or for $15-30$ minutes at $43^{\circ} \mathrm{C}$ are similar to those in cells treated with $41^{\circ} \mathrm{C}$, but more rapid.

The last group within the set of thermal doses employed here encompasses the reaction of cells that are subjected to 60 minutes at $43{ }^{\circ} \mathrm{C}$, or temperatures higher than $43^{\circ} \mathrm{C}$. These thermal doses seem to not only induce HR-deficiency, but affect the cells in many more ways [36]. For example, consistent with previous studies, we find that heat's ability to directly kill cells and sensitize to irradiation is increased, and keeps doing so with longer treatment length $[14,15]$. In contrast, BRCA2 protein levels in the whole cell extract cease to decrease over time after the initial drop. However, similar to when cells are treated with a proteasome inhibitor, treatment with hyperthermia at $44{ }^{\circ} \mathrm{C}$ causes BRCA2 to accumulate in a pellet fraction, while the amount of BRCA2 in the supernatant cell fraction keeps decreasing over time. This could be explained by possible defects in the functionality of the proteasome, which interferes with the molecular removal of unfolding BRCA2 proteins [37]. Consistent with this reaction, RAD51 focus morphology, the readout used to determine functionality of BRCA2, alters greatly in this last group. We show that foci become much smaller in size and somewhat less in intensity and that they appear independently of irradiation, indicating they form spontaneously upon heat. These structures resemble RAD51 foci described before to form independent of the BRCA2 protein, and could be stalled replication forks [22]. The possibility that hyperthermia $>43{ }^{\circ} \mathrm{C}$ directly affects progression in S-phase has previously been described, and is supported by the low intensity of the EdU-signal in cells treated in our assays, which is indicative of a lack in DNA synthesis [16]. All these findings prove that many more biological mechanisms than HR are affected by temperatures surpassing $43{ }^{\circ} \mathrm{C}$ and that these mechanisms result in a lower specificity of the heat treatment.

Concluding, our study demonstrates that if hyperthermia treatment is aimed at optimally inhibiting HR, the temperature which should be strived for is 42 ${ }^{\circ} \mathrm{C}$. The minimal thermal dose to achieve defects in this DNA repair pathway is $41^{\circ} \mathrm{C}$ for one hour, but it is not necessary to surpass 30 minutes at $43{ }^{\circ} \mathrm{C}$. Taking into consideration that in current hyperthermia treatments temperatures higher than $43^{\circ} \mathrm{C}$ are rarely reached in the patient [31], our findings can be regarded as reassuring of the current clinical guidelines and possibilities, but can be used to guide technological development of next generation hyperthermia systems. Moreover, it demonstrates that BRCA2 degradation and RAD51 focus formation could both be potential biomarkers for efficiency of hyperthermia treatment. However, the acquired data will be of particular interest as a guideline for potential clinical application of anti-cancer strategies that exploit the heat-mediated attenuation of HR, such as PARP-inhibitors [24, 25] or proton therapy [38, 39], will be combined with hyperthermia in a clinical setting $[8,12]$.

\section{MATERIALS AND METHODS}

\section{Experimental set-up, hyperthermia and irradiation}

We studied the effects of hyperthermia on HR by exposing cells in $60 \mathrm{~mm}$ petri dishes to increased temperatures ranging from $40-44{ }^{\circ} \mathrm{C}$ in an incubator with a controlled atmosphere $\left(5 \% \mathrm{CO}_{2}\right.$ and $\left.20 \% \mathrm{O}_{2}\right)$ set at the appropriate temperature. Indicated treatment times always exclude the 15 minutes required for the medium to reach the set temperature. The control samples were treated at $37{ }^{\circ} \mathrm{C}$. The cells were exposed to $\gamma$-irradiation from a caesium-137 source with a dose rate of $0.64 \mathrm{~Gy} / \mathrm{min}$ within 15 minutes after hyperthermia treatment.

\section{Cell culture}

The following four human cell lines were used: BLM, HeLa, FaDu and VH10-SV40. All cell lines were cultured in a 1:1 mixture of DMEM $(4.5 \mathrm{~g} / \mathrm{L}$ Glucose, with Ultraglutamine 1) and Ham's F-10 (BioWhittaker ${ }^{\mathrm{TM}}$ ), supplemented with $10 \%$ fetal calf serum and 1\% penicillin/streptomycin (Sigma-Aldrich), and were maintained in an incubator set at $37{ }^{\circ} \mathrm{C}$ and with an atmosphere of $5 \% \mathrm{CO}_{2}$ and $20 \% \mathrm{O}_{2}$. Frozen aliquots from same passages were used to minimize experimental variation. The cells were mycoplasma-free and distinguished by morphology. 


\section{Clonogenic assays}

Cells were allowed to recover from freezing by being cultured for six days: after thawing on day one, the cells were split on day 2 and were allowed to grow exponentially. Finally on day 5, 24 hours prior to seeding the clonogenic assay, $2 * 10^{6} \mathrm{BLM}$ or Hela cells and $3 * 10^{6} \mathrm{FaDu}$ or VH10-SV40 were seeded in $10 \mathrm{~cm}$ dishes. At the end of the sixth day, cells were trypsinized, counted with a coulter counter and seeded in triplicates at different concentrations in $60 \mathrm{~mm}$ dishes; for the control irradiation (0 Gy), 200 BLM or HeLa cells were seeded, or 300 for either FaDu or VH10-SV40. The amount of seeded cells was doubled for each 2 Gy increase in irradiation dose. The cells were allowed to attach overnight $(\sim 14 \mathrm{~h})$ and were treated with the different thermal doses and irradiation the next morning. Cell colonies were allowed to form for 10 days (HeLa and BLM) or 20 days (FaDu and VH10-SV40), after which they were fixed and stained in $45 \%$ methanol, $45 \% \mathrm{dH}_{2} \mathrm{O}, 10 \%$ Acetic acid and $0.25 \%$ Coomassie Brilliant Blue (Sigma-Aldrich). Colonies containing more than 30 cells were counted using a stereomicroscope.

\section{Cell lysis and protein assay}

The day before the experiment, $0.8 * 10^{6}$ (BLM and Hela) or $1.2 * 10^{6}(\mathrm{FaDu}$ and VH10-SV40) cells were seeded in a $60 \mathrm{~mm}$ dish. All cell lysates were made within 30 minutes after hyperthermia treatment, and were in the incubator together with the cells used for clonogenic survival or immunofluorescence analysis. After washing with PBS, the cells were scraped and then lysed in Laemmli sample buffer (2\% SDS, $10 \%$ Glycerol and $60 \mathrm{mM}$ Tris pH 6.8) and heated at $95^{\circ} \mathrm{C}$ for 5 minutes. The sample was passed through a syringe several times to reduce viscosity.

For fractionation experiments, cells in $15 \mathrm{~cm}$ dishes were treated with MG132 (Calbiochem) one hour before the start of hyperthermia, or without MG132 at the indicated temperatures. Immediately following treatment, the cells were lysed in NETT buffer $(50 \mathrm{mM}$ Tris- $\mathrm{HCl} \mathrm{pH} 7.5,100 \mathrm{mM} \mathrm{NaCl}, 5 \mathrm{mM}$ EDTA $0.5 \%$ Triton-X-100, $1 \mathrm{x}$ protease inhibitors (Complete, Roche ${ }^{\circledR}$ ) and $1 \mathrm{mM}$ pefabloc). After 30 minutes, the cells were scraped and centrifuged at $12000 \mathrm{rpm}$ for 15 minutes at $4{ }^{\circ} \mathrm{C}$. After centrifugation, the pellet and supernatant were separated and the pellet was resuspended in PBS. Laemmli buffer was added to both samples and the mixture was boiled at $95{ }^{\circ} \mathrm{C}$ for 5 minutes. Before immunoblotting, the protein concentration was estimated using the Lowry protein assay [40], after which protein samples were prepared by adding loading buffer (final concentration: $0.01 \%$ bromophenol blue and $0.5 \% \beta$-mercaptoethanol).

\section{Immunoblotting}

The samples were run on an SDS-PAGE gel or a 3-8\% Tris-Act gel (Novex, ThermoFisher Scientific). Protein transfer on a PVDF membrane was achieved by wet blotting at $300 \mathrm{~mA}$ for two hours at $4{ }^{\circ} \mathrm{C}$, using transfer buffer ( $0.4 \mathrm{M}$ Glycine, $5 \mathrm{mM}$ Tris, $20 \%$ Methanol). After transfer, the membrane was blocked in 3\% dry skimmed milk in PBS with $0.05 \%$ Tween- 20 . The primary antibody was incubated overnight at $4{ }^{\circ} \mathrm{C}$ and the secondary antibody was incubated for 1-2 hours at room temperature. After adding ECL substrate (1:1 mixture of A: $0.1 \mathrm{M}$ Tris- $\mathrm{HCl} \mathrm{pH} 8.5,2.5 \mathrm{mM}$ Luminol,

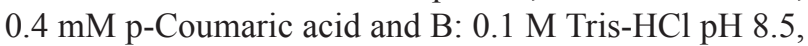
$0.02 \%$ hydrogen peroxide), blots were imaged in Alliance 4.7 (Uvitec Cambridge). The antibody signals from the immunoblots were quantified using the 'Analyze Gels' tool in FIJI (Image J1.50i, [41]). Equal protein loading was always checked by staining the post-transfer gel with Colloidal Coomassie $(0.008 \%$ Coomassie Brilliant Blue $\mathrm{G}-250$ and $0.35 \%$ glacial $\mathrm{HCl}$ in distilled water) by heating for $\sim 25 \mathrm{~s}$, shaking for 30 minutes, and subsequent destaining using distilled water.

\section{EdU incorporation and cell fixation}

One day prior to the experiment, $0.4 * 10^{6}$ Hela cells were seeded in a coverslip-containing $30 \mathrm{~mm}$ dish. The cells were fixed after hyperthermia treatment and irradiation. To distinguish S-phase cells, $10 \mu \mathrm{M}$ EdU (Invitrogen) was added to the cells 45 minutes prior to fixation. After the indicated time after irradiation, the cells were rinsed with PBS and subsequently incubated for 1 minute in a pre-extraction buffer containing Triton-X-100 (0.5\% Triton-X-100; 20 mM HEPES-KOH, pH 7.9; $50 \mathrm{mM} \mathrm{NaCl} ; 3 \mathrm{mM} \mathrm{MgCl}$ and $300 \mathrm{mM}$ sucrose) [42]. After rinsing with PBS, the cells were fixed by incubating them for 15 minutes in 4\% paraformaldehyde in PBS, followed by another wash in PBS.

\section{Immunofluorescence}

EdU was detected with the use of a Click-IT ${ }^{\circledR}$ reaction. First the cells were permeabilized with $0.5 \%$ Triton-X-100 for 30 minutes, then they were washed twice with 3\% BSA in PBS. Next, the cells were incubated for 45 minutes at room temperature in a cocktail containing a final dilution of $43 \mathrm{mM}$ Tris- $\mathrm{HCl} \mathrm{pH} 7.5,1.6 \mathrm{mM}$ $\mathrm{CuSO}_{4} \cdot 5 \mathrm{H}_{2} \mathrm{O}, 25 \mu \mathrm{M}$ ATTO 390 Azide (ATTO-TEC $\mathrm{GmbH}$ ) and $1 \mathrm{mM}$ Ascorbic Acid. Before labelling RAD51, the cells were washed once more with $3 \%$ BSA and continued by a wash step (three times a short wash and two times 10 minutes incubation with PBS $0.1 \%$ Triton-X-100), followed by 30 minutes blocking in PBS $+(0.5 \%$ BSA and $0.15 \%$ Glycine in PBS), overnight incubation at $4{ }^{\circ} \mathrm{C}$ with the first antibody in PBS+, another wash step, incubation with secondary antibody for two hours at room temperature. 
After another wash step and a short wash in PBS only, the samples were embedded in Vectashield (Vector Laboratories) and sealed with nail polish.

\section{Antibodies}

For immunoblotting, the following antibodies and dilutions were used: mouse anti-BRCA2 (1:1000, OP95, Ab-1, Merck Millipore), mouse anti-PARP-1 (1:5000, C2-10, Enzo Lifesciences), mouse anti-HSP90 (1:1000, AC88, Abcam) and HRP-conjugated Sheep anti-mouse IgG $(\mathrm{H}+\mathrm{L})$ (1:2000, Jackson ImmunoResearch). For immunofluorescence rabbit anti-RAD51 (1:10000, [43]) and an Alexa Fluor ${ }^{\circledR} 594$ goat anti-mouse (1:1000) were used.

\section{Image acquisition and foci counting}

The images were obtained with a Leica TCS SP5 confocal microscope, using the $63 \mathrm{x}$ oil immersion (n.a. 1.4) objective with an image size of $1024 \times 1024$ pixels and $82 \times 82 \mu \mathrm{m}$. Per coverslip, at least four areas that contained EdU-positive cells were imaged in Z-stacks with 14 slices and an increment of $1 \mu \mathrm{m}$. Before image analysis, maximum projections were made using FIJI image analysis software (Image J1.50i, [41]). For quantification of foci a homemade image analysis macro within FIJI was used. In short, regions of interest (ROIs) in the EdUchannel were selected, and within these ROIs a threshold was set for RAD51 positive spots using the MaxEntropy algorithm. The 'Analyze Particles' function was used to count particles with a minimum size of $0.05 \mathrm{~nm}$ and a maximum size of $5 \mathrm{~nm}$.

\section{Statistics}

All graphs and statistical analyses were generated in GraphPad Prism 6.0. Statistical tests for each experiment can be found in the figure legends.

\section{Author contributions}

NvdT, GvR, MF and RK designed experiments, $\mathrm{NvdT}, \mathrm{HO}$ and $\mathrm{CL}$ performed experiments. $\mathrm{WvC}$ and NvdT designed FIJI-macro for quantification of RAD51foci. GvR, MF and RK supervised project. NvdT, GvR, MF and RK wrote the manuscript, which was subsequently edited by all authors.

\section{ACKNOWLEDGMENTS}

We thank Dr. M.M. Paulides and Dr. B. Eppink for their valuable advice during the study design phase.

\section{CONFLICTS OF INTEREST}

The authors declare that there are no conflicts of interest.

\section{FUNDING}

This study was supported by an Erasmus MC MRace grant and by the Dutch Cancer Society (DDHK 2013-6072 and EMCR 2015-7846).

\section{REFERENCES}

1. van der Zee J, Vujaskovic Z, Kondo M, Sugahara T. The Kadota Fund International Forum 2004--clinical group consensus. Int J Hyperthermia. 2008; 24: 111-22.

2. Horsman MR, Overgaard J. Hyperthermia: a potent enhancer of radiotherapy. Clin Oncol. 2007; 19: 418-26.

3. Issels RD. Hyperthermia adds to chemotherapy. Eur J Cancer. 2008; 44: 2546-54.

4. Hildebrandt B. The cellular and molecular basis of hyperthermia. Crit Rev Oncol Hematol. 2002; 43: 33-56.

5. Dewhirst MW, Vujaskovic Z, Jones E, Thrall D. Re-setting the biologic rationale for thermal therapy. Int $\mathrm{J}$ Hyperthermia. 2005; 21: 779-90.

6. Dewhirst MW, Lee CT, Ashcraft KA. The future of biology in driving the field of hyperthermia. Int J Hyperthermia. 2016; 32: 4-13.

7. Issels R, Kampmann E, Kanaar R, Lindner LH. Hallmarks of hyperthermia in driving the future of clinical hyperthermia as targeted therapy: translation into clinical application. Int J Hyperthermia. 2016; 32: 89-95.

8. van den Tempel N, Horsman MR, Kanaar R. Improving efficacy of hyperthermia in oncology by exploiting biological mechanisms. Int J Hyperthermia. 2016; 32: 446-54.

9. Krawczyk PM, Eppink B, Essers J, Stap J, Rodermond H, Odijk H, Zelensky A, van Bree C, Stalpers LJ, Buist MR, Soullié T, Rens J, Verhagen HJM, et al. Mild hyperthermia inhibits homologous recombination, induces BRCA2 degradation, and sensitizes cancer cells to poly (ADPribose) polymerase-1 inhibition. Proc Natl Acad Sci U S A. 2011; 108: 9851-6.

10. Moynahan ME, Pierce AJ, Jasin M. BRCA2 is required for homology-directed repair of chromosomal breaks. Mol Cell. 2001; 7: 263-72.

11. Jasin M, Rothstein R. Repair of strand breaks by homologous recombination. Cold Spring Harb Perspect Biol. 2013; 5: a012740.

12. Eppink B, Krawczyk PM, Stap J, Kanaar R. Hyperthermiainduced DNA repair deficiency suggests novel therapeutic anti-cancer strategies. Int J Hyperthermia. 2012; 28: 509-17.

13. Oei AL, Vriend LE, van Leeuwen CM, Rodermond HM, Ten Cate R, Westermann AM, Stalpers LJ, Crezee J, Kanaar R, Kok HP, Krawczyk PM, Franken NA. Sensitizing thermochemotherapy with a PARP1-inhibitor. Oncotarget. 2017; 8: 16303-12. doi: 10.18632/oncotarget.11422.

14. Dewey WC, Hopwood LE, Sapareto SA, Gerweck LE. Cellular responses to combinations of hyperthermia and radiation. Radiology. 1977; 123: 463-74. 
15. Field SB, Morris CC. The relationship between heating time and temperature: its relevance to clinical hyperthermia. Radiother Oncol. 1983; 1: 179-86.

16. Roti Roti JL. Cellular responses to hyperthermia (4046 degrees $\mathrm{C}$ ): cell killing and molecular events. Int J Hyperthermia. 2008; 24: 3-15.

17. Franken NA, Rodermond HM, Stap J, Haveman J, van Bree C. Clonogenic assay of cells in vitro. Nat Protoc. 2006; 1: 2315-9.

18. Thorslund T, West SC. BRCA2: a universal recombinase regulator. Oncogene. 2007; 26: 7720-30.

19. van Veelen LR, Cervelli T, van de Rakt MW, Theil AF, Essers J, Kanaar R. Analysis of ionizing radiation-induced foci of DNA damage repair proteins. Mutat Res. 2005; 574: 22-33.

20. Agarwal S, Tafel AA, Kanaar R. DNA double-strand break repair and chromosome translocations. DNA Repair (Amst). 2006; 5: 1075-81.

21. Agarwal S, van Cappellen WA, Guenole A, Eppink B, Linsen SE, Meijering E, Houtsmuller A, Kanaar R, Essers J. ATP-dependent and independent functions of Rad54 in genome maintenance. J Cell Biol. 2011; 192: 735-50.

22. Tarsounas M, Davies D, West SC. BRCA2-dependent and independent formation of RAD51 nuclear foci. Oncogene. 2003; 22: 1115-23.

23. Oei AL, Vriend LE, Crezee J, Franken NA, Krawczyk PM. Effects of hyperthermia on DNA repair pathways: one treatment to inhibit them all. Radiat Oncol. 2015; 10: 165.

24. Farmer H, McCabe N, Lord CJ, Tutt AN, Johnson DA, Richardson TB, Santarosa M, Dillon KJ, Hickson I, Knights C, Martin NM, Jackson SP, Smith GC, et al. Targeting the DNA repair defect in BRCA mutant cells as a therapeutic strategy. Nature. 2005; 434: 917-21.

25. Bryant HE, Schultz N, Thomas HD, Parker KM, Flower D, Lopez E, Kyle S, Meuth M, Curtin NJ, Helleday T. Specific killing of BRCA2-deficient tumours with inhibitors of poly(ADP-ribose) polymerase. Nature. 2005; 434: 913-7.

26. Lord CJ, Ashworth A. PARP inhibitors: synthetic lethality in the clinic. Science. 2017; 355: 1152-8.

27. Dinges S, Harder C, Wurm R, Buchali A, Blohmer J, Gellermann J, Wust P, Randow H, Budach V. Combined treatment of inoperable carcinomas of the uterine cervix with radiotherapy and regional hyperthermia. Results of a phase II trial. Strahlenther Onkol. 1998; 174: 517-21.

28. Rau B, Wust P, Tilly W, Gellermann J, Harder C, Riess H, Budach V, Felix R, Schlag PM. Preoperative radiochemotherapy in locally advanced or recurrent rectal cancer: regional radiofrequency hyperthermia correlates with clinical parameters. Int J Radiat Oncol Biol Phys. 2000; 48: 381-91.

29. van der Zee J, Gonzalez Gonzalez D, van Rhoon GC, van Dijk JD, van Putten WL, Hart AA. Comparison of radiotherapy alone with radiotherapy plus hyperthermia in locally advanced pelvic tumours: a prospective, randomised, multicentre trial. Dutch Deep Hyperthermia Group. Lancet. 2000; 355: 1119-25.

30. Franckena M, Stalpers LJ, Koper PC, Wiggenraad RG, Hoogenraad WJ, van Dijk JD, Warlam-Rodenhuis CC, Jobsen JJ, van Rhoon GC, van der Zee J. Long-term improvement in treatment outcome after radiotherapy and hyperthermia in locoregionally advanced cervix cancer: an update of the Dutch Deep Hyperthermia Trial. Int J Radiat Oncol Biol Phys. 2008; 70: 1176-82.

31. Franckena M, Fatehi D, de Bruijne M, Canters RA, van Norden Y, Mens JW, van Rhoon GC, van der Zee J. Hyperthermia dose-effect relationship in 420 patients with cervical cancer treated with combined radiotherapy and hyperthermia. Eur J Cancer. 2009; 45: 1969-78.

32. Linthorst $M$, Baaijens M, Wiggenraad R, Creutzberg C, Ghidey W, van Rhoon GC, van der Zee J. Local control rate after the combination of re-irradiation and hyperthermia for irresectable recurrent breast cancer: results in 248 patients. Radiother Oncol. 2015; 117: 217-22.

33. Horsman MR. Realistic biological approaches for improving thermoradiotherapy. Int J Hyperthermia. 2016; 32: 14-22.

34. Song CW, Shakil A, Osborn JL, Iwata K. Tumour oxygenation is increased by hyperthermia at mild temperatures. Int J Hyperthermia. 2009; 25: 91-5.

35. Datta NR, Ordóñez SG, Gaipl US, Paulides MM, Crezee H, Gellermann J, Marder D, Puric E, Bodis S. Local hyperthermia combined with radiotherapy and-/or chemotherapy: recent advances and promises for the future. Cancer Treat Rev. 2015; 41: 742-53.

36. Kampinga HH, Dikomey E. Hyperthermic radiosensitization: mode of action and clinical relevance. Int J Radiat Biol. 2001; 77: 399-408.

37. Pajonk F, Van Ophoven A, McBride WH. Hyperthermiainduced proteasome inhibition and loss of androgen receptor expression in human prostate cancer cells. Cancer Res. 2005; 65: 4836-43.

38. Grosse N, Fontana AO, Hug EB, Lomax A, Coray A, Augsburger M, Paganetti H, Sartori AA, Pruschy M. Deficiency in homologous recombination renders mammalian cells more sensitive to proton versus photon irradiation. Int J Radiat Oncol Biol Phys. 2014; 88: 175-81.

39. Fontana AO, Augsburger MA, Grosse N, Guckenberger M, Lomax AJ, Sartori AA, Pruschy MN. Differential DNA repair pathway choice in cancer cells after proton- and photon-irradiation. Radiother Oncol. 2015; 116: 374-80.

40. Lowry OH, Rosebrough NJ, Farr AL, Randall RJ. Protein measurement with the Folin phenol reagent. J Biol Chem. 1951; 193: 265-75.

41. Schindelin J, Arganda-Carreras I, Frise E, Kaynig V, Longair M, Pietzsch T, Preibisch S, Rueden C, Saalfeld S, Schmid B, Tinevez JY, White DJ, Hartenstein V, et al. Fiji: an open source platform for biological image analysis. Nat Methods. 2012; 9: 676-82. 
42. Zhu XD, Küster B, Mann M, Petrini JH, de Lange T. Cellcycle-regulated association of RAD50/MRE11/NBS1 with TRF2 and human telomeres. Nat Genet. 2000; 25: 347-52.

43. Essers J, Hendriks RW, Wesoly J, Beerens CE, Smit B,
Hoeijmakers JH, Wyman C, Dronkert ML, Kanaar R. Analysis of mouse Rad54 expression and its implications for homologous recombination. DNA Repair (Amst). 2002; 1: 779-93. 